\title{
The Role of Current Family Relationships in Associations Between Childhood Abuse and Adult Psychological Functioning
}

\author{
Jooyoung Kong, PhD, ${ }^{1}$ Sara M. Moorman, PhD, ${ }^{2}$ Lynn M. Martire, PhD, ${ }^{1,3}$ and \\ David M. Almeida, PhD ${ }^{1,3}$
}

${ }^{1}$ Center for Healthy Aging, College of Health and Human Development, Pennsylvania State University, University Park. ${ }^{2}$ Department of Sociology, Institute on Aging, Boston College, Chestnut Hill, Massachusetts. ${ }^{3}$ Human Development and Family Studies, Pennsylvania State University, University Park.

Address correspondence to: Jooyoung Kong, PhD, Center for Healthy Aging, Pennsylvania State University, University Park, PA 16802.

E-mail: jzk255@psu.edu.

Received: July 12, 2017; Editorial Decision Date: June 11, 2018

Decision Editor: J. Jill Suitor, PhD

\begin{abstract}
Objectives: Childhood abuse has long-term negative effects on adult psychological well-being. This study examined whether and how adults with a history of childhood abuse may experience poor psychological functioning partly due to aspects of current family relationships.

Method: We estimated multilevel mediation models using 3 waves of longitudinal data from 3,487 participants in the study of Midlife Development in the United States. Outcomes measured included negative affect, life satisfaction, and psychological well-being. We included aspects of family relationships as mediators: perceived support, perceived strain, frequency of contact, and hours of providing instrumental and emotional support.

Results: Multilevel mediation models showed that childhood verbal and physical abuse negatively affected diverse aspects of family relationships in later adulthood (i.e., less perceived support, more perceived strain, less frequent contact, and fewer hours of providing instrumental support). We also found that less perceived support and more family strain significantly mediated the associations between childhood abuse and all 3 psychological functioning outcomes.

Discussion: Childhood abuse appears to hinder perceived availability of family support in adulthood, which may undermine the psychological functioning of adults with a history of childhood abuse. To improve their psychological health, interventions should focus on facilitating supportive and functional family relationships.
\end{abstract}

Keywords: Childhood adversity, Family support, Psychological well-being

The lifelong adverse health effects of parental childhood abuse have been well-documented, such that adults with a history of childhood abuse are more likely to experience mental health problems (e.g., mood and/or anxiety disorders) and diminished psychological well-being (Green et al., 2010; Sugaya et al., 2012). Much research has also identified individual and interpersonal mechanisms linking childhood abuse to psychological health in later adulthood, including emotional dysregulation, a lack of social competence, or impaired intimate relationships (Alink, Cicchetti, Kim, \& Rogosch, 2012; Repetti, Taylor, \& Seeman, 2002).

However, fewer systematic efforts have been made to examine the role of contemporary family relationships in the association between parental childhood abuse and 
psychological functioning in later life. The quality and characteristics of current family relationships are shaped by past events, situations, or relational dynamics that have been accumulated over time (Antonucci, Birditt, Sherman, \& Trinh, 2011). We posit that parental childhood abuse can have long-term negative repercussions for family relationships in later adulthood that include both the family of origin and the family of procreation.

The current study aimed to examine whether aspects of contemporary family relationships entailing perceived support and strain, contact frequency, and the level of social support provision would mediate the association between a history of childhood abuse and adult psychological functioning. Two decades of life-course data from the National Survey of Midlife Development in the United States (MIDUS) were analyzed. We present theoretical contributions, as well as specific practice implications, to improve the psychological functioning of adults with a history of childhood abuse.

\section{Theoretical Frameworks: Family Relationships and Psychological Functioning in Late Adulthood}

The convoy model of social relations (Antonucci et al., 2011; Kahn \& Antonucci, 1980) serves as a theoretical framework to explain the long-term effect of childhood abuse on adult family relationships and psychological functioning outcomes. Convoys refer to "the social relationships that surround the individual at various stages in the life cycle, providing opportunities to give and receive social support" (Larner, 1993, p. 183). Primary convoy members are often family such as spouses/partners, children, parents, and siblings with whom the individual feels very close and exchanges many types of support to fulfill each other's emotional and instrumental needs (Ajrouch, Blandon, \& Antonucci, 2005; Antonucci \& Akiyama, 1987).

A major tenet of the convoy model suggests that the quality and characteristics of family relationships can influence individual health and well-being (Antonucci, Flori, Birditt, \& Jackey, 2010; Antonucci et al., 2011). Family relationships are multifaceted and intricate; the essence of family relationships can be indexed by several distinct-butinterrelated dimensions, including the perceived quality of the relationships (e.g., emotional closeness), frequency of contact, and levels of social support exchanged (Bengtson, Giarrusso, Mabry, \& Silverstein, 2002; Roberts, Richards, \& Bengtson, 1991). Existing studies have consistently provided evidence that having highly cohesive and functional family relationships, as characterized by high perceived closeness and frequent associations through contact and the exchange of social support, can positively impact the health and psychological well-being of individuals (Fingerman, Sechrist, \& Birditt, 2013; Merz, Consedine, Schulze, \& Schuengel, 2009; Ward, 2008).

\section{Childhood Abuse as a Potent Life-Course Factor for Adult Family Relationships and Psychological Functioning}

Rooted in the life course perspective (Elder, 1994) and in the convoy model, the current study postulates that the childhood experience of being abused by parents can negatively affect psychological functioning in later adulthood through the aspects of adult family relationships. First, well-established evidence supports significant linkages between the exposure to childhood abuse and negative psychological health outcomes in later life (Coates, Dinger, Donovan, \& Phares, 2013; Norman et al., 2012). For example, Herrenkohl, Klika, Herrenkohl, Russo, and Dee (2012) conducted prospective research finding that adults who had been involved with child welfare services due to abuse and neglect showed higher depression, more pronounced anxiety, and a greater risk of substance use compared with those with no known child welfare involvement. Similar results have been found in most other studies which have relied on adults' retrospective reports of child abuse, rather than on state records. Greenfield and Marks (2010) examined the associations between profiles of parental physical and psychological abuse during childhood and adult mental health outcomes based on the MIDUS national sample. The key results showed that not only the frequent experience of either or both types of childhood abuse, but also occasional experiences (i.e., reporting "rarely" to the abuse items) predicted more negative affect and less psychological well-being in adulthood. Using cross-sectional data from MIDUS I (1995-1996), Schafer, Morton, and Ferraro (2014) considered two different retrospective reports of childhood experience: parent-child relationship quality and parental maltreatment. The authors found an interesting pattern, namely that a substantial proportion of adults who reported having been frequently maltreated evaluated their childhood relationship with the perpetrating parent as positive (i.e., reporting "good," "very good," or "excellent"). Worsened health outcomes in adulthood were most prominent among adults who experienced maltreatment and reported negative parent-child relationships. These results emphasize the complexities involved in the associations between abuse history, one's evaluation of family relationships, and health outcomes.

In terms of the associations between childhood abuse and adult family relationships, only scant literature exists. Using the MIDUS I sample, Shaw and Krause (2002) found that childhood physical abuse was negatively associated with perceived emotional support from family and positively associated with perceived negative interactions with family members in later life. Similarly, Savla and colleagues (2013) analyzed data from MIDUS II (2004-2006), finding that childhood verbal abuse negatively affected the levels of emotional closeness with family (measured by indicators of perceived family support and strain) in later adulthood. Based on the same data set, a recent study by 
Parker, Maier, and Wojciak (2016) found that adults with a history of childhood abuse and neglect reported a lower perceived obligation to family than did nonabused adults.

A small but growing number of studies examined the long-term effect of childhood abuse on later relationship outcomes with the perpetrating parent. For example, Kong and Moorman (2016) examined the association between a history of maternal childhood abuse and the frequency of social support provided to aging mothers using the MIDUS II sample. The results indicated that a history of maternal childhood abuse was associated with providing less frequent emotional support to aging mothers, although the level of instrumental support provided was not significantly affected. In addition, Kong (2018) showed that adults with a history of maternal childhood abuse evaluated their relationship with aging mothers as being less close compared to their nonabused counterparts, which was ultimately associated with reduced psychological well-being.

\section{Present Study}

The prior studies reviewed suggest that the harmful effects of childhood abuse persist into adulthood, potentially undermining contemporary family relationships as well as psychological functioning in later life. The contributions of the current study are threefold. First, we considered diverse aspects of family relationships as potential mediators linking childhood abuse and psychological functioning in later adulthood. Second, childhood abuse typically occurs in the context of multiple family and social problems. Because child victims are often exposed to other risk factors simultaneously, such as poverty, family disruption, or parental substance use issues (Lansford et al., 2015; Savla et al., 2013), we controlled for confounding factors of other adverse childhood experiences (i.e., parental divorce, socioeconomic hardships). This approach allowed us to distinguish between childhood abuse and other childhood adversities in terms of examining their respective long-term effects. Third, while many previous studies were based on cross-sectional data and thus lacked a robust statistical test of mediational effects, we used rigorous data analysis methods (i.e., multilevel structural equation modeling) to analyze three-wave longitudinal data from the MIDUS. Our hypothesis was that diverse aspects of contemporary family relationships would mediate the association between histories of childhood abuse and adult psychological functioning. That is, we expected that adults with a history of childhood abuse will report less perceived support from family, more perceived strain, less frequent contact, and lower levels of social support, which could ultimately contribute to poor psychological functioning.

\section{Method}

\section{Data Set and Study Sample}

This study used data from the National Survey of Midlife Development in the United States (MIDUS). The first wave of MIDUS was conducted in 1995-1996, surveying a sample of 7,108 noninstitutionalized English-speaking adults aged 25-74. Follow-up surveys were conducted in 20042006 (MIDUS II) and 2013-2014 (MIDUS III), with high retention rates (e.g., $77 \%$ of living participants responded to the MIDUS III telephone survey). We restricted the analysis to 3,487 respondents from the national random digit dialing (RDD) sample to improve data representativeness and avoid clustering within family units. Table 1 presents descriptive statistics of the study sample characteristics. At the time of the MIDUS I data collection, about half of the sample was male $(49 \%, n=1,721), 74 \%$ were white $(n=2,586)$, and the average age was 46 years with a range of 20-74 years. Among this study sample, 2,257 respondents $(74 \%)$ participated in MIDUS II, and 1,414 $(47 \%)$ participated in MIDUS III. The current study used unweighted data for data analyses. Compared with the Current Population Survey sample, which closely resembles the demographic makeup of the United States, the unweighted MIDUS sample under-represented African Americans and less-educated individuals (high school graduates or adults with less than a high school education).

\section{Measures}

All of the key variables were measured at all three waves, except for the two measures of childhood abuse (collected at MIDUS I only), and the measure of other childhood adversity (collected at MIDUS II only).

\section{Independent Variables}

Childhood verbal abuse

Verbal abuse was measured by averaging the responses of the two items from the Conflict Tactics Scale (CTS; Bernstein et al., 1994; Straus, Gelles, \& Steinmetz, 1980; Cronbach's alpha: 0.61): "During your childhood, how often did your (a) mother or the woman raised you, (b) father or the man raised you, insult you or swear at you, sulk or refuse to talk to you, stomp out of the room, do or say something to spite you, threaten to hit you, smash or kick something in anger?" Respondents rated the items on a 4 -point scale $(1=$ never, $2=$ rarely, $3=$ sometimes, $4=$ often $)$.

\section{Childhood physical abuse}

Physical abuse was measured by averaging the responses of the following four items from the CTS (Bernstein et al., 1994; Straus et al., 1980; Cronbach's alpha: 0.76): "During your childhood, how often did (a) your mother or the woman raised you, (b) father or the man raised you push, grab, or shove you, slap you, throw something at you?, (c) your mother or the woman raised you, (d) father or the man raised you, kick, bite, or hit you with a fist, hit or try to hit you with something, beat you up, choke you, burn or scald you?" Respondents rated the items on a 4 -point scale $(1=$ never, 2 rarely, 
Table 1. Summary Statistics of Study Sample and Key Variables

\begin{tabular}{|c|c|c|}
\hline Variables & N/Mean $(S D)$ & \%/Observed min./max. \\
\hline \multicolumn{3}{|l|}{ History of childhood abuse $\mathrm{a}^{\mathrm{a}}$} \\
\hline Childhood verbal abuse & $1.81(0.80)$ & $1-4$ \\
\hline Childhood physical abuse & $1.47(0.57)$ & $1-4$ \\
\hline \multicolumn{3}{|l|}{ Aspects of current family relationship ${ }^{\mathrm{b}}$} \\
\hline Perceived support from family & $3.49(0.54)$ & $1-4$ \\
\hline Perceived strain with family & $2.10(0.55)$ & $1-4$ \\
\hline Frequency of contact with family & $5.90(1.56)$ & $1-8$ \\
\hline Hours of providing emotional support & $45.57(55.32)$ & $0-200$ \\
\hline Hours of providing instrumental support & $11.43(18.76)$ & $0-70$ \\
\hline \multicolumn{3}{|l|}{ Adult psychological functioning ${ }^{\mathrm{b}}$} \\
\hline Negative affect & $1.53(0.55)$ & $1-3$ \\
\hline Life satisfaction & $7.75(1.63)$ & $0-10$ \\
\hline Psychological well-being & $5.51(0.80)$ & $1.75-7$ \\
\hline \multicolumn{3}{|l|}{ Sociodemographic covariates } \\
\hline \multicolumn{3}{|l|}{ Gender $^{\mathrm{a}}$} \\
\hline Male & 1,721 & 49.35 \\
\hline Female & 1,766 & 50.65 \\
\hline \multicolumn{3}{|l|}{ Race $^{\mathrm{a}}$} \\
\hline White & 2,586 & 74.16 \\
\hline Others & 360 & 10.32 \\
\hline \multicolumn{3}{|l|}{ Marital status ${ }^{\mathrm{b}}$} \\
\hline Married & - & 64.33 \\
\hline Nonmarried & - & 35.67 \\
\hline \multicolumn{3}{|l|}{ Self-rated health ${ }^{\mathrm{b}}$} \\
\hline Excellent/very good/good & - & 83.63 \\
\hline Fair/poor & - & 16.37 \\
\hline Age $^{\mathrm{a}}$ & $46.42(13.23)$ & $20-74$ \\
\hline Educational attainment ${ }^{\mathrm{c}}$ & $7.11(2.54)$ & $1-12$ \\
\hline \multicolumn{3}{|l|}{ Childhood environmental covariates } \\
\hline Family-related childhood adversity ${ }^{\mathrm{c}}$ & $0.42(0.68)$ & $0-3$ \\
\hline Low childhood SES ${ }^{c}$ & $3.92(1.29)$ & $1-7$ \\
\hline
\end{tabular}

Note: Higher mean scores indicate higher levels of a variable. Unweighted data were used.

${ }^{a}$ Measurements at the MIDUS I. b Averages across three time-points. 'Measurements at the MIDUS II.

3 = sometimes, $4=$ often $)$. Childhood verbal and physical abuse variables were moderately correlated $(r=.68$, $p<.001)$.

\section{Mediators}

Perceived support from family

Perceived support from family was assessed with eight items that asked about respondents' perceptions of support availability from the spouse (partner) and other family members. First, four items were asked regarding relationships with the spouse: (a) "How much does your spouse or partner really care about you?" (b) "How much does he/ she understand the way you feel about things?" (c) "How much can you rely on him/her for help if you have a serious problem?" and (d) "How much can you open up to him/ her if you need to talk about your worries?" The same set of four questions was asked regarding the relationship with family (e.g., "Not including your spouse or partner, how much do members of your family really care about you?”).
Respondents rated the items on a 4-point scale $(1=$ not at all, $2=$ a little, $3=$ some, $4=a$ lot $)$. The total score was calculated by averaging the eight items (Cronbach's alpha at MIDUS I: 0.82).

Perceived strain with family

Perceived strain with the spouse and other family members were assessed with eight items. First, four items were asked regarding relationships with the spouse: How often does your spouse or partner (a) "make too many demands on you?" (b) "criticize you?" (c) "let you down when you are counting on him/her?" (d) "get on your nerves?" The same set of four questions was asked regarding the relationship with family (e.g., "Not including your spouse or partner, how often do members of your family make too many demands on you?"). Respondents rated the items on a 4 -point scale $(1=$ never, $2=$ rarely, $3=$ sometimes, $4=$ often $)$. The total score was calculated by averaging the eight items (Cronbach's alpha at MIDUS I: 0.80). 
Frequency of contact with family

Frequency of contact with family was assessed by a single item that asked: "How often are you in contact with any members of your family, that is, any of your brothers, sisters, parents, or children who do not live with you, including visits, phone calls, letters, or electronic mail messages?" Respondents rated the item on an 8-point scale (1 = never or hardly ever, 2 = less than once a month, 3 = about once a month, 4 = two or three times a month, 5 = about once a week, 6 = several times a week, 7 = about once a day, 8 = several times a day).

Hours of providing social support

Participants reported hours of providing emotional and instrumental support to family members over a month of time. First, emotional support given was measured by four items: "On average, about how many hours per month do you spend giving informal emotional support (such as comforting, listening to problems, or giving advice) to your (a) spouse, (b) parents or the people who raised you, (c) in-laws, (d) children or grandchildren?" To deal with extreme values, the variable was top-coded at the 95th percentile of the distribution, which was $200 \mathrm{hr}$ of providing emotional support a month. Second, instrumental support given was measured by three items: "On average, about how many hours per month do you spend providing unpaid assistance (such as help around the house, transportation, or childcare) to (a) parents or the people who raised you, (b) in-laws, (c) children or grandchildren?" To deal with extreme values, the variable was top-coded at the 95th percentile of the distribution, which was $70 \mathrm{hr}$ of providing instrumental support a month.

\section{Dependent Variables \\ Negative affect}

Negative affect was measured by the K6 scale (Kessler et al., 2003). The six items include "During the past 30 days, how much of the time did you feel (a) so sad nothing could cheer you up; (b) nervous; (c) restless or fidgety; (d) hopeless; (e) that everything was an effort; and (f) worthless?" Respondents rated the items on a 5 -point scale $(1=$ none of the time, 2 = a little of the time, 3 = some of the time, $4=$ most of the time, $5=$ all of the time). The total score was calculated by averaging the six items (Cronbach's alpha at MIDUS I: 0.87). The skewness of the variable was corrected by top-coding the variable at 3 .

\section{Life satisfaction}

Life satisfaction was measured by a single item (Prenda $\&$ Lachman, 2001) that asked: "How would you rate your life overall these days?" Respondents rated the items on a 10 -point scale $(0=$ the worst possible to $10=$ the best possible).

Psychological well-being

Psychological well-being was measured by the Ryff Scale of Psychological Well-being (Ryff \& Keyes, 1995). We used a total of 18 items that were consistently measured across the three waves (e.g., "I have confidence in my opinions even if they are contrary to the general consensus," "In general, I feel I am in charge of the situation in which I live.”). Respondents rated the items on a 7-point scale ( 1 = strongly disagree to $7=$ strongly agree $)$. The total score was calculated by averaging the 18 items (Cronbach's alpha at MIDUS I: 0.80).

\section{Control Variables}

Several covariates were added to control for sociodemographic characteristics, including respondents' gender, race (white, other), marital status (currently married, currently unmarried), age (in years), self-rated health (excellent/very good/good, fair/poor), and education (1 = no school/some grade school to $12=\mathrm{PhD}$ level degree). Marital status and self-rated health were included as time-varying covariates. Based on the Adverse Family Experiences scale (AFEs; Heerman, Krishnaswami, Barkin, \& McPheeters, 2016), we created a family-related adversity variable that consisted of the sum of six items that asked whether the respondent ever experienced (a) their parent being out of a job, (b) being on welfare, (c) parent(s)' drinking problems, (d) parent(s)' drug problems, (e) a parent's death, and (f) parents' divorce. We also considered childhood socioeconomic status (SES), which was measured by a single item that asked: "When you were growing up, was your family better off or worse off financially than the average family was at that time?" Respondents rated the item on a 7-point scale $(1=$ a lot better off to $7=$ a lot worse off .

\section{Analytic Strategy}

To test our hypothesis, we conducted multilevel structural equation modeling (MSEM). When applied to longitudinal data, MSEM partitions the variance of a time-varying variable into a latent within-person component (fluctuation over time relative to the person's own mean) and a latent between-person component (person-level means across time points), which are then used to calculate between- and within-person covariance matrices (Preacher, Zyphur, \& Zhang, 2010). MSEM estimates a mediation model that involves the independent variable at the Level 2 (betweenpersons) level and the mediators and outcomes at the Level 1 (within-persons) levels without introducing conflation or bias in estimating indirect effects (Preacher et al., 2010). In the current study, using the two-level option in Mplus Version 6, our MSEM model included one time-invariant predictor (childhood abuse), five time-varying mediators (i.e., perceived support, perceived strain, frequency of contact, and the hours of providing emotional support and instrumental support to family) and three time-varying outcomes (i.e., negative affect, life satisfaction, and psychological well-being), estimated with random intercepts and fixed slopes. It was a partial mediational model with additional direct paths from a history of childhood abuse to outcome 
variables. We emphasize that because a history of childhood abuse is a time-invariant predictor, the current mediational model can only predict family relationships and psychological functioning outcomes between individuals rather than longitudinally within an individual (Figure 1). That is, our focal interest was to examine whether and how between-person variability in contemporary family relationships would mediate a history of childhood abuse and between-person variability in psychological functioning outcomes over time. The benefit of using longitudinal data is then to go beyond the measurement at a single moment in time and analyze multiple observations over an extended period of time.

Our MSEM model used robust maximum likelihood estimation (MLR), and full information maximum likelihood (FIML) accommodated for missing data (i.e., 37\% complete data across the three waves) and unbalanced cluster sizes (i.e., each person's number of observations). In terms of evaluating the goodness of fit of the hypothesized model, we assessed separate model fit at the within- and between-person levels by producing estimates of saturated covariance matrices at each level (Ryu, 2014). The model fit was evaluated based on the suggestions by $\mathrm{Hu}$ and Bentler (1998).

\section{Results}

Table 1 presents summary statistics for key variables. On average, respondents reported that they rarely experienced parental verbal and physical abuse during childhood based on the 4-point scale $(M=1.81, S D=0.80 ; M=1.47$, $S D=0.57$, respectively). The average level of perceived support from family across the three waves was 3.49 (range $1-4 ; S D=0.54)$, and that of perceived strain with family was 2.10 (range 1-4; $S D=0.55$ ). On average, the respondents contacted their family several times a week $(M=5.90$, $S D=1.56$ ). In addition, they provided emotional support to family members for about $46 \mathrm{hr}$ a month on average across the three waves $(S D=55.32)$ and provided instrumental support for $11.43 \mathrm{hr}$ a month $(S D=18.76)$.

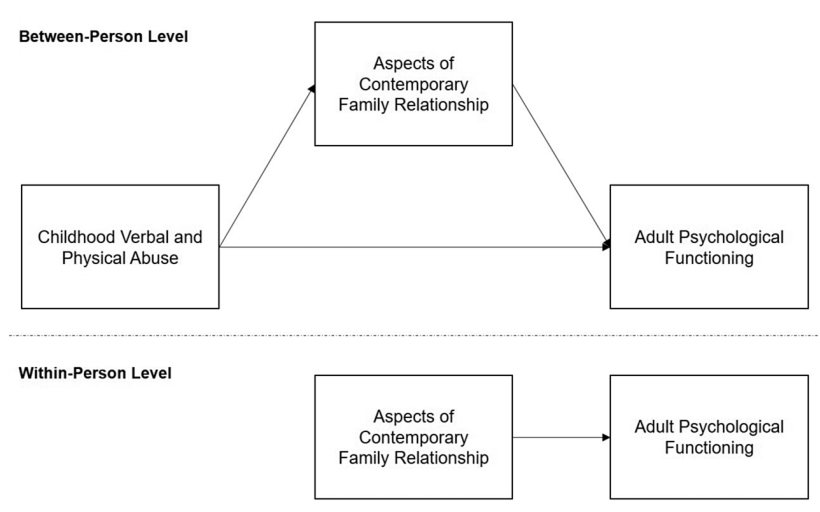

Figure 1. Conceptual model of multilevel mediation.

\section{MSEM Estimates of Between-Person Associations}

Our key focus was between-person direct and indirect associations among childhood abuse, aspects of family relationships, and psychological outcomes (Figure 1). Overall, the model fit the data well (between-person level: $\chi^{2}=922.516$, $p<.001 ;$ RMSEA $=0.04 ;$ CFI $=0.92 ;$ SRMR $=0.07$ ). In terms of the between-person direct effects (Table 2), histories of childhood verbal and physical abuse predicted less perceived support $(b=-0.09, p<.001 ; b=-0.07, p<.01)$ and greater perceived strain with family $(b=0.11, p<.001$; $b=0.08, p<.01)$. Childhood physical abuse was associated with less frequent contact $(b=-0.19, p<.01)$ and fewer hours of providing instrumental support $(b=-1.40$, $p<.05)$ at the between-person level. In turn, perceived support was positively associated with life satisfaction and psychological well-being $(b=1.06 ; b=0.51, p s<.001)$. Perceived strain was positively associated with negative affect $(b=0.29, p<.001)$ and negatively associated with life satisfaction and psychological well-being $(b=-0.57$; $b=-0.33$, ps $<.001)$.

Table 3 shows the results of the indirect effects that linked childhood abuse, the aspects of current family relationships, and psychological outcomes. Both childhood verbal and physical abuse were positively associated with negative affect through perceived strain with family $(b=0.03, p<.001 ; b=0.02, p<.01)$. Also, childhood verbal and physical abuse were negatively associated with life satisfactions and psychological well-being through between-person differences in perceived support and perceived strain. We note that although the coefficients are statistically significant, their size is not substantively large. Nonetheless, the effect size reflects a one unit increase in the measurements of childhood abuse and thus we expect incremental effects as the intensity/ frequency of childhood abuse increases. We also consider the effect sizes in an additive manner as multiple paths are simultaneously contributing to the levels of psychological functioning.

\section{Supplementary Analyses}

Distinction between family of origin and family of procreation

Using the available measures in MIDUS, we were unable to separate relationships according to family of origin and family of procreation. To address this limitation, we conducted a series of supplementary analyses. First, to examine the effect of childhood abuse on relationships within the family of origin, we narrowed our sample to the 522 respondents, who at baseline, were never married and childless and reported having a parent alive. Our logic is that these individuals were referring primarily to the family of origin when answering the general family support measures. Because of the small size of this sample across time, 
Table 2. Multilevel Structural Equation Modeling Estimates of Between-Person Direct Effects

\begin{tabular}{|c|c|c|}
\hline Between-person direct effects & Unstandardized Estimates (SE) & Standardized Estimates \\
\hline Childhood verbal abuse $\rightarrow$ Perceived support & $-0.09(0.02) * * *$ & $-0.17 * * *$ \\
\hline Childhood physical abuse $\rightarrow$ Perceived support & $-0.07(0.03)^{* *}$ & $-0.11^{* *}$ \\
\hline Childhood verbal abuse $\rightarrow$ Perceived strain & $0.11(0.02)^{* * * *}$ & $0.23 * * *$ \\
\hline Childhood physical abuse $\rightarrow$ Perceived strain & $0.08(0.02) * *$ & $0.11 * * *$ \\
\hline Childhood verbal abuse $\rightarrow$ Frequency of contact & $-0.04(0.04)$ & -0.04 \\
\hline Childhood physical abuse $\rightarrow$ Frequency of contact & $-0.19(0.07)^{* *}$ & $-0.11 * *$ \\
\hline Childhood verbal abuse $\rightarrow$ Emotional support given & $1.08(1.43)$ & 0.03 \\
\hline Childhood physical abuse $\rightarrow$ Emotional support given & $2.05(1.96)$ & 0.04 \\
\hline Childhood verbal abuse $\rightarrow$ Instrumental support given & $0.58(0.51)$ & 0.05 \\
\hline Childhood physical abuse $\rightarrow$ Instrumental support given & $-1.40(0.68)^{*}$ & $-0.09 *$ \\
\hline Perceived support $\rightarrow$ Negative affect & $-0.09(0.05)$ & -0.09 \\
\hline Perceived support $\rightarrow$ Life satisfaction & $1.06(0.16)^{* * *}$ & $0.38 * * *$ \\
\hline Perceived support $\rightarrow$ Psychological well-being & $0.51(0.08) * * *$ & $0.32 * * *$ \\
\hline Perceived strain $\rightarrow$ Negative affect & $0.29(0.04)^{* * * *}$ & $0.30 * * *$ \\
\hline Perceived strain $\rightarrow$ Life satisfaction & $-0.57(0.12) * * *$ & $-0.21 * * *$ \\
\hline Perceived strain $\rightarrow$ Psychological well-being & $-0.33(0.06) * * *$ & $-0.21 * * *$ \\
\hline Frequency of contact $\rightarrow$ Negative affect & $-0.03(0.02)$ & -0.07 \\
\hline Frequency of contact $\rightarrow$ Life satisfaction & $0.07(0.06)$ & 0.06 \\
\hline Frequency of contact $\rightarrow$ Psychological well-being & $0.06(0.03)$ & $0.10 *$ \\
\hline Emotional support given $\rightarrow$ Negative affect & $0.00(0.00)$ & 0.06 \\
\hline Emotional support given $\rightarrow$ Life satisfaction & $-0.00(0.00)$ & -0.03 \\
\hline Emotional support given $\rightarrow$ Psychological well-being & $0.00(0.00)$ & 0.09 \\
\hline Instrumental support given $\rightarrow$ Negative affect & $0.00(0.00)$ & -0.00 \\
\hline Instrumental support given $\rightarrow$ Life satisfaction & $0.01(0.01)$ & 0.07 \\
\hline Instrumental support given $\rightarrow$ Psychological well-being & $-0.00(0.00)$ & -0.05 \\
\hline Childhood verbal abuse $\rightarrow$ Negative affect & $0.07(0.01)^{* * *}$ & $0.15 * *$ \\
\hline Childhood physical abuse $\rightarrow$ Negative affect & $-0.02(0.02)$ & -0.04 \\
\hline Childhood verbal abuse $\rightarrow$ Life satisfaction & $-0.09(0.04)^{*}$ & $-0.07 *$ \\
\hline Childhood physical abuse $\rightarrow$ Life satisfaction & $0.14(0.06)^{*}$ & $0.07 *$ \\
\hline Childhood verbal abuse $\rightarrow$ Psychological well-being & $-0.02(0.02)$ & -0.03 \\
\hline Childhood physical abuse $\rightarrow$ Psychological well-being & $0.05(0.03)$ & 0.05 \\
\hline
\end{tabular}

Note: We did not include the results of the within-person effects as our focus was to examine the between-person mediational associations. $* p<.05 . * p<.01 . * * p<.001$.

Table 3. Multilevel Structural Equation Modeling Estimates of Between-Person Indirect Effects

\begin{tabular}{llc}
\hline Between-person indirect effects & Unstandardized Estimates (SE) & Standardized Estimates \\
\hline Childhood verbal abuse $\rightarrow$ Perceived strain $\rightarrow$ Negative affect & $0.03(0.01)^{* * *}$ & $0.07^{* * *}$ \\
Childhood physical abuse $\rightarrow$ Perceived strain $\rightarrow$ Negative affect & $0.02(0.01)^{* *}$ & $0.03 * *$ \\
Childhood verbal abuse $\rightarrow$ Perceived support $\rightarrow$ Life satisfaction & $-0.09(0.02)^{* * *}$ & $-0.07 * * *$ \\
Childhood physical abuse $\rightarrow$ Perceived support $\rightarrow$ Life satisfaction & $-0.08(0.03)^{* *}$ & $-0.04 * *$ \\
Childhood verbal abuse $\rightarrow$ Perceived strain $\rightarrow$ Life satisfaction & $-0.06(0.02)^{* * *}$ & $-0.05^{* * *}$ \\
Childhood physical abuse $\rightarrow$ Perceived strain $\rightarrow$ Life satisfaction & $-0.05(0.02)^{* *}$ & $-0.02^{* *}$ \\
Childhood verbal abuse $\rightarrow$ Perceived support $\rightarrow$ Psychological well-being & $-0.04(0.01)^{* * *}$ & $-0.06^{* * *}$ \\
Childhood physical abuse $\rightarrow$ Perceived support $\rightarrow$ Psychological well-being & $-0.04(0.01)^{* *}$ & $-0.03^{* *}$ \\
Childhood verbal abuse $\rightarrow$ Perceived strain $\rightarrow$ Psychological well-being & $-0.04(0.01)^{* * *}$ & $-0.05^{* * *}$ \\
Childhood physical abuse $\rightarrow$ Perceived strain $\rightarrow$ Psychological well-being & $-0.03(0.01)^{* * *}$ & $-0.02^{* *}$ \\
\hline
\end{tabular}

Note: Only significant indirect effects are shown.

$* p<.05 . * p<.01 * * * p<.001$.

we performed cross-sectional structural equation modeling using the MIDUS I data. The overall results showed that, consistent with the results of the original MSEM model, perceived family support and strain were the significant mediators linking histories of childhood abuse and later psychological outcomes (Supplementary Table A). 
Additionally, we examined the subsample of respondents whose parents had both died before MIDUS I data collection. For these individuals, the general family support measures cannot reflect an ongoing relationship with an abusive parent. Their family support responses were referring to nonparental family members of origin (e.g., siblings, aunts, and uncles) as well as members of the family of procreation. This approach yielded a sample size of 726 at MIDUS I, 491 at MIDUS II, and 267 at MIDUS III. We estimated the identical MSEM model, and the results are summarized in Supplementary Table B. We found consistent results indicating that perceived support and strain were the significant mediators linking childhood abuse and psychological outcomes in later adulthood, although only childhood verbal abuse was found to be a significant predictor for the mediational model.

These findings may indicate that the psychological effects of physical abuse primarily have to do with a continued relationship with the abusive parent, while the psychological effects of verbal abuse are sustained through overall family relationships. The specific characteristics of abuse history (i.e., types of abuse) may have different implications for later family relationships. Future research is warranted to present more robust empirical evidence than we can provide here.

\section{Temporal ordering of the mediational associations}

To tease apart the causal order between the aspects of family relationships and psychological outcomes, we conducted supplementary analyses using the mediators and outcome variables measured at different points in time. The results revealed that some paths involving childhood abuse, family support at MIDUS II, and psychological outcomes at MIDUS III were statistically significant, whereas there were no statistically significant paths involving childhood abuse, psychological outcomes at MIDUS II, and family support at MIDUS III. These results support our key findings, which were also supported by the theoretical tenet of the convoy model, that is, that aspects of family relationships may serve as mediating links between childhood abuse and adult psychological functioning.

\section{Selective attrition}

Logistic regression analyses predicting attrition $(0=$ retained, $1=$ attrited $)$ indicated that those more likely to attrite were male, nonwhite, and unmarried, and further that they reported worse self-reported health, and had lower levels of education. Also, adults with a more frequent experience of childhood verbal abuse were less likely to attrite. To understand whether and how this pattern of attrition might have affected the results of the MSEM analysis, we performed supplementary analyses as suggested by Rubin (1987) by imputing the values of attriters and then re-estimated the model using the complete data set. Results were consistent with those presented in Tables 2 and 3 , with one exception. In the imputed data, childhood physical abuse was associated with less frequent contact with family, which was in turn associated with greater negative affect and lower levels of life satisfaction and psychological well-being. This aspect of the findings aside, we conclude that our results are unlikely to have been biased by selective attrition.

\section{Discussion}

Families, despite variance in structure and functioning, are the major source of social support and comfort for individuals throughout their lifetime, and thus the quality of family relationships and functioning significantly influences individual well-being and health (Antonucci et al., 2011; Fuller-Iglesias, Webster, \& Antonucci, 2015). The current article evaluated whether and how this premise applies to adults with histories of childhood abuse. We considered childhood abuse as a life-course factor that can impact individuals' psychological functioning in later adulthood through the aspects of current family relationships.

\section{Effects of Childhood Abuse Persist in Adult Family Relationships}

Consistent with prior studies (e.g., Savla et al., 2013), our findings suggest that a history of childhood abuse may negatively affect diverse aspects of family relationships in later adulthood. Specifically, greater frequencies of childhood verbal and physical abuse were found to be associated with less perceived positive support and more perceived strain in family relationships, after accounting for other family-related adversities during childhood (e.g., parental substance problems, low childhood SES). In addition, childhood physical abuse was associated with less frequent contact and fewer hours of providing instrumental support to overall family members. Antonucci, Ajrouch, and Birditt (2014) noted that social relations can vary by the individual's personal and situational characteristics. The current study supports that idea by showing that dysfunctional family histories and past events, such as parental childhood abuse, may constitute significant life-course factors that have long-term negative implications for later family relationships.

The hypothesis of the current study was partially supported by the data: negative perceptions of family support (i.e., less perceived support and more perceived strain) significantly mediated the associations between childhood verbal/physical abuse and psychological functioning outcomes. The health benefits of the perceived availability of family support are well-established in the existing literature (Martire \& Schulz, 2012). Adults with histories of childhood abuse appear to be deprived of the full extent of these benefits; furthermore, a lack of beliefs and perceptions regarding supportive relationships with family may serve to impair outcomes in psychological functioning. 
It is important to note that individual perceptions about overall family relationships, rather than objective frequency of contact or the actual hours spent providing social support, were significant mechanisms linking childhood abuse and psychological functioning in later adulthood. This result is consistent with prior studies showing that the individual's evaluation of relationship quality has more impact on health and well-being than other objective characteristics of relationships, such as social network size or social support exchange (Antonucci et al., 2010; Antonucci, Fuhrer, \& Dartigues, 1997; Kong, 2018; Schafer et al., 2014). We cannot rule out the possibility that these perceptions may reflect actual family relationships that involve less supportive and more conflicting interactions. Alternatively, negative internal working models (i.e., perceiving the self as being unworthy and unlovable and others as untrustworthy, nonresponsive, and rejecting), one major correlate of childhood abuse, might have been projected in the family relationships, diminishing the availability of positive support and amplifying negative interactions (Kong \& Moorman, 2016; Schwarz \& Trommsdorff, 2005). Additionally, unresolved emotional issues and/or ongoing relational difficulties with family members may be the source of negative perceptions toward family support.

As mentioned above, the levels of instrumental and emotional support provided were not found to mediate the associations between childhood abuse and adult psychological functioning. These results are inconsistent with existing studies that have shown significant associations between the provision of social support and individual well-being (Thomas, 2010), a discrepancy which may suggest that the effects may be pronounced in the context where individuals have tangible needs and resources (Djundeva, Mills, Wittek, \& Steverink, 2015). Relatedly, the nonsignificant association between providing support and psychological functioning may be attributed to the sample characteristics that individuals of low SES tend to be under-represented. For abused adults who require extensive physical and financial support, as well as for those with such family members, the level of connectedness sustained through contact and social support provision may have significant implications for psychological health outcomes, which warrants future research.

\section{Limitations and Implications}

This study has limitations which must be noted. First, the current study used retrospective self-reports of childhood abuse that may involve recall errors (Macmillan, 2009). The measures are also limited in assessing detailed information regarding the context of abuse, such as timing or duration. However, the measurement has the merit of having the ability to identify abuse cases that are not referred for services or prosecution. Second, we were not able to precisely untangle the effects of abuse on relationships with the family of origin and family of procreation using the available measures of family relationships. Third, the original MIDUS sample may not reflect characteristics of the general population; this concern is more pronounced when attrition is considered across the waves of the longitudinal study. Consistent with the findings of Radler and Ryff (2010), who investigated sociodemographic factors associated with longitudinal retention in the MIDUS data collection, our attrition analysis indicated that those more likely to attrite were male, nonwhite, nonmarried, reporting worse self-reported health, and having lower levels of education. Also, adults with less more frequent experience of childhood verbal abuse were less likely to attrite at MIDUS II and MIDUS III. The results suggest that, overall, socioeconomically disadvantaged individuals tend to be under-represented in the study sample. The sample characteristics may contribute to underestimate the effect sizes of mediational associations, as the study sample possesses several protective sociodemographic factors that might have offset the negative impact of childhood abuse.

Despite the noted limitations, this study provides important practice implications. Adults with histories of childhood abuse should be aware that past adverse experiences have lingering negative effects on their current family relationships. When intervening to ameliorate the mental health concerns of adults with a history of childhood abuse, practitioners should carefully assess their contemporary family relationships and help them address unresolved issues or ongoing challenges with family, if applicable. Furthermore, an understanding of the ways in which the violence experienced from the family of origin may spill over into the family relationships established in adulthood (i.e., the family of procreation) will be beneficial in terms of detaching the negative influence of childhood abuse on current family relationships (Gostečnik, 2017). Practitioners could also intervene in alleviating previously abused adults' negative perceptions toward family function and availability and directing their attentions and efforts to improve family relationships and functioning. For example, intervention programs that aim to improve the communication skills of adults who were abused as children may prove beneficial for facilitating positive family interactions, and further for promoting psychological functioning (Segrin \& Flora, 2004).

\section{Supplementary Material}

Supplementary data are available at The Journals of Gerontology, Series B: Psychological Sciences and Social Sciences online.

\section{Funding}

This study was supported by National Institute on Aging (T32 AG049676 to D. M. Almeida and K02 AG039412 to L. M. Martire) to The Pennsylvania State University. Since 1995 the MIDUS study has been funded by the following: John D. and Catherine T. MacArthur Foundation Research Network, National Institute on Aging (P01-AG020166), and National institute on Aging (U19-AG051426). 


\section{Acknowledgments}

Author Contributions: J. Kong planned the study, performed all statistical analyses, and wrote the paper. S. M. Moorman helped plan the study, supervised statistical analyses, and assisted in writing and revising the article. L. M. Martire reviewed statistical analyses and assisted in writing and revising the article. D. M. Almeida reviewed statistical analyses and helped revise the article.

\section{Conflict of Interest}

None reported.

\section{References}

Ajrouch, K. J., Blandon, A. Y., \& Antonucci, T. C. (2005). Social networks among men and women: The effects of age and socioeconomic status. The Journals of Gerontology, Series B: Psychological Sciences and Social Sciences, 60, S311-S317. doi:10.1093/geronb/60.6.S311

Alink, L. R., Cicchetti, D., Kim, J., \& Rogosch, F. A. (2012). Longitudinal associations among child maltreatment, social functioning, and cortisol regulation. Developmental Psychology, 48, 224-236. doi:10.1037/a0024892

Antonucci, T. C., Ajrouch, K. J., \& Birditt, K. S. (2014). The convoy model: Explaining social relations from a multidisciplinary perspective. The Gerontologist, 43, 82-92. doi: 10.1093/geront/ gnt118

Antonucci, T. C., \& Akiyama, H. (1987). Social networks in adult life and a preliminary examination of the convoy model. Journal of Gerontology, 42, 519-527.

Antonucci, T. C., Birditt, K. S., Sherman, C. W., \& Trinh, S. (2011). Stability and change in the intergenerational family: A convoy approach. Ageing and Society, 31, 1084-1106. doi:10.1017/ S0144686X1000098X

Antonucci, T. C., Fiori, K. L., Birditt, K. S., \& Jackey, L. M. H. (2010). Convoys of social relations: Integrating life-span and life-course perspectives. In R. M. Lerner, M. E. Lamb, A. M. Freund (Eds.), The handbook of life-span development (pp. 434-473). Hoboken, NJ: Wiley.

Antonucci, T. C., Fuhrer, R., \& Dartigues, J. F. (1997). Social relations and depressive symptomatology in a sample of community-dwelling French older adults. Psychology and Aging, 12, 189-195. doi:10.1037/0882-7974.12.1.189

Bengtson, V. L., Giarrusso, R., Mabry, J., \& Silverstein, M. (2002). Solidarity, conflict, and ambivalence: Complementary or competing perspectives on intergenerational relationships? Journal of Marriage and Family, 64, 568-576. doi:10.1111/j.1741-3737.2002.00568.x

Bernstein, D. P., Fink, L., Handelsman, L., Foote, J., Lovejoy, M., Wenzel, K.,...Ruggiero, J. (1994). Initial reliability and validity of a new retrospective measure of child abuse and neglect. The American Journal of Psychiatry, 151, 1132-1136. doi:10.1176/ ajp.151.8.1132

Coates, E. E., Dinger, T., Donovan, M., \& Phares, V. (2013). Adult psychological distress and self-worth following child verbal abuse. Journal of Aggression, Maltreatment and Trauma, 22, 394-407. doi:10.1080/10926771.2013.775981
Djundeva, M., Mills, M., Wittek, R., \& Steverink, N. (2015). Receiving instrumental support in late parent-child relationships and parental depression. The Journal of Gerontology, Series B: Psychological Sciences and Social Sciences, 70, 981994. doi:10.1093/geronb/gbu136

Elder, G. H. (1994). Time, human agency, and social change: Perspectives on the life course. Social Psychology Quarterly, 57, 4-15. doi:10.2307/2786971

Fingerman, K. L., Sechrist, J., \& Birditt, K. (2013). Changing views on intergenerational ties. Gerontology, 59, 64-70. doi:10.1159/000342211

Fuller-Iglesias, H. R., Webster, N. J., \& Antonucci, T. C. (2015). The complex nature of family support across the life span: Implications for psychological well-being. Developmental Psychology, 51, 277-288. doi:10.1037/a0038665

Gostečnik, C. (2017). Relational family therapy: The systemic, interpersonal, and intrapsychic experience. New York, NY: Routledge.

Green, J. G., McLaughlin, K. A., Berglund, P. A., Gruber, M. J., Sampson, N. A., Zaslavsky, A. M., \& Kessler, R. C. (2010). Childhood adversities and adult psychiatric disorders in the national comorbidity survey replication I: Associations with first onset of DSM-IV disorders. Archives of General Psychiatry, 67, 113-123. doi:10.1001/archgenpsychiatry.2009.186

Greenfield, E. A., \& Marks, N. F. (2010). Identifying experiences of physical and psychological violence in childhood that jeopardize mental health in adulthood. Child Abuse \& Neglect, 34, 161-171. doi:10.1016/j.chiabu.2009.08.012

Heerman, W. J., Krishnaswami, S., Barkin, S. L., \& McPheeters, M. (2016). Adverse family experiences during childhood and adolescent obesity. Obesity (Silver Spring, Md.), 24, 696-702. doi:10.1002/oby.21413

Herrenkohl, T. I., Klika, J. B., Herrenkohl, R. C., Russo, M. J., \& Dee, T. (2012). A prospective investigation of the relationship between child maltreatment and indicators of adult psychological well-being. Violence and Victims, 27, 764-776. doi:10.1891/0886-6708.27.5.764

Hu, L. T., \& Bentler, P. M. (1998). Fit indices in covariance structure modeling: Sensitivity to underparameterized model misspecification. Psychological Methods, 3, 424-453. doi:10.1037/1082-989X.3.4.424

Kahn, R. L., \& Antonucci, T. C. (1980). Convoys over the life course: Attachment, roles, and social support. In P. B. Baltes \& O. Brim (Eds.) Life-span development and behavior (pp. 253-268). New York: Academic Press.

Kessler, R. C., Barker, P. R., Colpe, L. J., Epstein, J. F., Gfroerer, J. C., Hiripi, E.,...Zaslavsky, A. M. (2003). Screening for serious mental illness in the general population. Archives of General Psychiatry, 60, 184-189. doi:10.1001/archpsyc.60.2.184

Kong, J. (2018). Childhood maltreatment and psychological well-being in later life: The mediating effect of contemporary relationships with the abusive parent. The Journals of Gerontology, Series B: Psychological Sciences and Social Sciences, 73, e39-e48. doi: 10.1093/geronb/gbx039

Kong, J., \& Moorman, S. M. (2016). History of childhood abuse and intergenerational support to mothers in adulthood. Journal of Marriage and Family, 78, 926-938. doi:10.1111/ jomf.12285 
Lansford, J.E., Godwin, J., Uribe Tirado, L. M.,Zelli,A.,Al-Hassan, S. M., Bacchini, D.,...Peña Alampay, L. (2015). Individual, family, and culture level contributions to child physical abuse and neglect: A longitudinal study in nine countries. Development and Psychopathology, 27, 1417-1428. doi:10.1017/S095457941500084X

Larner, M. (1993). Changes in network resources and relationships over time. In M. Cochran, M. Larner, D. Riley, L. Gunnarsson, \& C. R. Henderson, Jr. (Eds), Extending families: The social networks of parents and their children (pp. 181-204). New York, NY: Cambridge University Press.

Macmillan, R. (2009). The life course consequences of abuse, neglect, and victimization: Challenges for theory, data collection, and methodology. Child Abuse \& Neglect, 33, 661-665. doi:10.1016/j.chiabu.2009.09.002

Martire, L. M., \& Schulz, R. (2012). Caregiving and care-receiving in later life: Recent evidence for health effects and promising intervention approaches. In A. Baum, T. Revenson, and J. Singer (Eds), Handbook of health psychology (2nd ed., pp. 293-307). New York: Psychology Press/Taylor and Francis.

Merz, E., Consedine, N., Schulze, H., \& Schuengel, C. (2009). Wellbeing of adult children and ageing parents: Associations with intergenerational support and relationship quality. Ageing and Society, 29, 783-802. doi:10.1017/S0144686X09008514

Norman, R. E., Byambaa, M., De, R., Butchart, A., Scott, J., \& Vos, T. (2012). The long-term health consequences of child physical abuse, emotional abuse, and neglect: A systematic review and meta-analysis. PLOS Medicine, 9, e1001349. doi:10.1371/ journal.pmed.1001349

Parker, E. O., \& Maier, C., \& Wojciak, A. (2016). Childhood abuse and family obligation in middle adulthood: Findings from the MIDUS II National Survey. Journal of Family Therapy, 40, 120 141. doi:10.1111/1467-6427.12114

Preacher, K. J., Zyphur, M. J., \& Zhang, Z. (2010). A general multilevel SEM framework for assessing multilevel mediation. Psychological Methods, 15, 209-233. doi:10.1037/a0020141

Prenda, K. M., \& Lachman, M. E. (2001). Planning for the future: A life management strategy for increasing control and life satisfaction in adulthood. Psychology and Aging, 16, 206-216. doi:10.1037//0882-7974.16.2.206

Radler, B. T., \& Ryff, C. D. (2010). Who participates? Accounting for longitudinal retention in the MIDUS national study of health and well-being. Journal of Aging and Health, 22, 307-331. doi:10.1177/0898264309358617

Repetti, R. L., Taylor, S. E., \& Seeman, T. E. (2002). Risky families: Family social environments and the mental and physical health of offspring. Psychological Bulletin, 128, 330366. doi:10.1037/0033-2909.128.2.330

Roberts, R., Richards, L., \& Bengtson, V. L. (1991). Intergenerational solidarity in families: Untangling the ties that bind. Marriage and Family Review, 16, 11-46. doi:10.1300/J002v16n01_02

Rubin, D. R. (1987). Multiple imputation for nonresponse in surveys. New York, NY: John Wiley \& Sons.

Ryff, C. D., \& Keyes, C. L. (1995). The structure of psychological well-being revisited. Journal of Personality and Social Psychology, 69, 719-727. doi:10.1037/0022-3514.69.4.719

Ryu, E. (2014). Model fit evaluation in multilevel structural equation models. Frontiers in Psychology, 5, 81. doi:10.3389/ fpsyg.2014.00081

Savla, J. T., Roberto, K. A., Jaramillo-Sierra, A. L., Gambrel, L. E., Karimi, H., \& Butner, L. M. (2013). Childhood abuse affects emotional closeness with family in mid- and later life. Child Abuse \& Neglect, 37, 388-399. doi:10.1016/j. chiabu.2012.12.009

Schafer, M. H., Morton, P. M., \& Ferraro, K. F. (2014). Child maltreatment and adult health in a national sample: Heterogeneous relational contexts, divergent effects? Child Abuse \& Neglect, 38, 395-406. doi:10.1016/j.chiabu.2013.08.003

Schwarz, B., \& Trommsdorff, G. (2005). The relation between attachment and intergenerational support. European Journal of Ageing, 2, 192-199. doi:10.1007/s10433-005-0005-x

Segrin, C., \& Flora, J. (2004). Family communication. Mahwah, NJ: Routledge.

Shaw, B. A., \& Krause, N. (2002). Exposure to physical violence during childhood, aging, and health. Journal of Aging and Health, 14, 467-494. doi:10.1177/089826402237179

Straus, M. A., Gelles, R. J., \& Steinmetz, S. (1980). Behind closed doors: Violence in the American family. New York, NY: Anchor Books.

Sugaya, L., Hasin, D. S., Olfson, M., Lin, K. H., Grant, B. F., \& Blanco, C. (2012). Child physical abuse and adult mental health: A national study. Journal of Traumatic Stress, 25, 384-392. doi:10.1002/jts.21719

Thomas, P. A. (2010). Is it better to give or to receive? Social support and the well-being of older adults. The Journals of Gerontology, Series B: Psychological Sciences and Social Sciences, 65, S351S357, doi:10.1093/geronb/gbp113

Ward, R. A. (2008). Multiple parent-adult child relations and well-being in middle and later life. The Journals of Gerontology, Series B: Psychological Sciences and Social Sciences, 63, S239S247. doi:10.1093/geronb/63.4.S239 